\title{
Representing Rhetoric:
}

\section{Post-truth and the Example of Thank You for Smoking}

Michael D. Donnelly

Ball State University

Muncie, IN

Poroi 16,2 (December 2021)

\begin{abstract}
Grounding assumptions about the function of public discourse are critical to the formation and functioning of society. One way of examining those assumptions is through analyzing how public discourse gets represented in popular culture. Patricia Roberts-Miller's (2004) taxonomy of models of public spheres serves as a template for the analysis of the film Thank You for Smoking (2006). This analysis demonstrates how the film both advocates for and contributes to the evolution of a post-truth public sphere by obscuring the historical controversy over tobacco. Truth and knowledge are not merely hidden or ignored but neutralized, and "spin" is therefore normalized and ultimately justified as a necessary protection of individual rights in a libertarian democracy.
\end{abstract}

Keywords: Post-truth, public discourse, film, tobacco industry

\section{Introduction}

Following his inauguration as President of the United States, Donald Trump claimed that attendance at the event was the largest ever. The next day White House Press Secretary Sean Spicer stated it was, "the largest audience ever to witness an inauguration" (Herschfeld and Rosenberg, 2017). Kellyanne Conway later defended Spicer's inaccurate comment by saying he was merely presenting "alternative facts" (Bradner, 2017). Later, after Trump falsely claimed that the U.S. murder rate was at its highest in 47 years, Newt Gingrich explained on CNN that this was also true because the "average American ... does not think crime is down"; when pressed on the fact that FBI statistics showed that violent crime across the country was in fact lower, Gingrich insisted that "what I said is also a fact" (McIntyre, 2018, pp. 3-4). Still later, 
during the investigation into Russia's tampering with the U.S. election, Rudy Giuliani (also appearing on $\mathrm{CNN}$ ), said quite clearly that "Truth is not truth" (Gomez, 2018).

It is perhaps not surprising, then, that less than two years earlier, Oxford Dictionaries had named "post-truth" its word of the year. Lee McIntyre (2018) points out that post-truth means more than just lying. It means, first and foremost, that in the realm of public argumentation, feelings and beliefs matter more than "facts" (p.5). Put differently, post-truth is an epistemological orientation in which "facts" become, merely, "opinions." Although I do not want to engage in the debate over whether post-truth signifies something actually new, it seems clear that post-truth is not a break or change from one thing to something completely different. It is, rather, an evolutionary development. In point of fact, I will argue, post-truth designates the quasi-logical evolution of a deranged version of the public sphere. I will pursue this argument by using Patricia Roberts-Miller's (2004) taxonomy of models of public spheres as a template for the analysis of a particular film, Jason Reitman's Thank You for Smoking (2006). The film itself does two important things: 1) it makes an argument about argument, about the function of public discourse, and in so doing, 2) it obscures and in large measure erases the actual historical facts about the tobacco industry and the debates over smoking cigarettes.

First, however, I want to establish some basic assumptions. Kenneth Burke (1969) asserted that rhetoric "is rooted in an essential function of language itself ... the use of language as a symbolic means of inducing cooperation in beings that by nature respond to symbols" (p. 43). Similarly, Jacques Derrida said, "we should not neglect the importance of rhetoric, as if it were simply a formal superstructure or technique exterior to the essential activity. Rhetoric is something decisive in society. ... There are no politics, there is no society without rhetoric, without the force of rhetoric"; he qualified this statement, however, by noting that he was "very suspicious of what I would call 'rhetoricism'-a way of giving rhetoric all the power, thinking that everything depends on rhetoric as simply a technique of speech" (Olson, 1990, p. 15; emphasis added).

I should like to suggest here that rhetoric - as the use of symbolic communication to coordinate social action-may not be "all there is," but what makes rhetoric decisive is not simply techniques of speech (that is, the use of symbolic communication to coordinate social action), but the theory of rhetoric (as public 
discourse) underlying or governing its use(s). In other words, not just rhetoric but a theory of rhetoric is fundamental to the way (a) society forms and functions. Moreover, in larger, more (so-called) "advanced" societies, multiple theories - or "models" - are always already in play, interacting and conflicting in complex ways.

I wish, then, to raise the question, what is the (assumed) function of rhetoric at the present time? In other words, in what ways is rhetoric itself re-presented - invoked, portrayed, conceptualized, understood (i.e., theorized) - in and by the society in which it functions? What tends to be assumed or understood about the function(s) of public discourse in American culture? In what ways are particular views of public discourse made dominant, marginal, subversive, or peripheral? Logical, sensible, taken-forgranted, or non-sensical? Moreover, what is the relationship between these assumptions about rhetoric and the politico-social arrangements in which they are embedded and which they function to support, justify, normalize, contest, and/or undermine?

In this sense, Jason Rietman's 2006 film Thank You for Smoking (based quite loosely on Christopher Buckley's novel of the same name) is both unique and instructive. It is unique in that it both features a modern-day "rhetorician" (not a lawyer or politician, per se, but a "lobbyist") as its main character; moreover, it explicitly proposes a theory of rhetoric; that is, it makes an argument about argument, about the purpose(s) and role(s) of public discourse. I would like to offer, then, an analysis of the film as a singular example of the representation of rhetoric in popular culture, a window into one important version of a public sphere. That is, Thank You for Smoking both illustrates and advocates a particular (and peculiar) notion of public discourse, one that privileges individual liberty (while equating that liberty with the "rights" of corporate giants), and thus rejects democratic deliberation as a meaningful goal of public discourse.

\section{Models of the Public Sphere}

Jürgen Habermas proposed the most famous version of a public sphere, a version which has been widely (and justifiably) critiqued. That model - the bourgeois or "liberal" model - was premised on principles of open, rational, democratic debate among relative equals ("status" having been checked at the door, so-to-speak). Although I do not wish to defend Habermas against his many detractors, I do wish to point out two key aspects of his

description. First, what Habermas was describing was never the 
public sphere, but $a$ public sphere, one that was specifically bourgeois (Calhoun, 1992, p. 7). Second, what was translated as "public sphere" - Öffentlichkeit - is more accurately called publicness; this term, according to John Durham Peters (1993), should be understood to encompass both an openness of debate (that is, the opening of channels for discussion and deliberation among the populace) and broad access to accurate information, on which the legitimacy of democratic debate depends (p. 542).

Understood this way, as a particular model of publicness, Habermas's description can be fruitfully compared to other kinds of models. In Deliberate Conflict, Patricia Roberts-Miller (2004) provides a useful taxonomy for such comparison. Among differing models of a public sphere, she lists - in addition to the liberal or bourgeois model - the technocratic, the interest-based, the deliberative, the agonistic, and the communitarian. Although the list is not intended to be exhaustive, and the categories are themselves not necessarily mutually exclusive, they highlight for us certain conflicting tendencies, which can illuminate the theoretical forces that shape public discourse. The technocratic model, for example, "assumes that policy questions are fundamentally technical questions and are best solved [by] technical experts"; in contrast, the interest-based model "assumes that people can and should look to their own self-interest in regard to public policies" (pp. 4-5). The deliberative model is similar to the liberal (bourgeois) model, but "assume[s] a much broader notion of argument ... one that includes narrative, attention to the particular, sensibility, and appeals to emotion" (pp. 4-5); both models tend to value disagreement as a part of the process that leads to the most beneficial conclusions. The agonistic model goes further still, placing the highest possible value on disagreement as inherently valuable in itself, and therefore resisting the closure of normative agreement.

In short, a model of the public sphere basically is a theory of how rhetoric functions or should function in society. RobertsMiller's taxonomy, then, will be useful in analyzing the particular (and peculiar) version of the public sphere that is both embodied in and advocated by the movie Thank You for Smoking. In turn, the film serves as an illustrative example of how public discourse is assumed to function - or, rather, the film makes an argument about how public discourse should function.

Although I will argue later that Reitman's movie is not actually about smoking at all - it is, rather, about the function of public discourse - it is especially significant that the movie takes 
smoking as its subject. As McIntyre (2018) points out, much of what we now call post-truth is rooted in science denial, which was "born in the debate about smoking" (p. 22). In fact, the CEOs of the major tobacco companies began, in 1953, to sponsor their own "research" with the express purpose of casting doubt on science that was linking smoking to cancer. I will return to actual historical details later, but for now, it is worth pointing out that the strategy pursued by the tobacco companies would provide a "blueprint" for future public debate over controversial issues: "Find and fund your own experts, use this to suggest to the media that there are two sides to the story, push your side through public relations and governmental lobbying, and capitalize on the resulting public confusion to question whatever scientific result you wish to dispute" (McIntyre, 2018, pp. 24-25). The movie Thank You for Smoking, in turn, pursues and contributes to this strategy by representing the public debate in a way that justifies and normalizes this particular version of the public sphere.

\section{Filtering (the) Truth}

Christopher Buckley's book, Thank You for Smoking, was published in 1994, what Buckley would later refer to as "the height of the P.C. movement" (Rose, 2006). Its main character, Nick Naylor, is the "chief spokesperson for the Academy of Tobacco Studies" (Buckley, 1994, p. 3), the official "research" organization funded by the major tobacco corporations. The novel is clear satire, showing Naylor bumbling his way through trying to defend the indefensible - that is, the tobacco industry, which has come under increasing fire over the adverse effects of smoking. Even before Buckley's novel was published, Mel Gibson had optioned the movie rights. There were, apparently, a number of different scripts written, but none ever made it to production. Then, Jason Reitman wrote his own version of a screenplay (on spec), and was promptly hired by Gibson (Buckley, 2006, p. 126). Even though (according to Buckley), Gibson said "it was brilliant and exactly the script he had hoped for and he would absolutely make it," still there was no movement on production. Then David Sacks, formerly chief operating officer of PayPal, became interested, and negotiated the rights to take the movie away from Gibson's company. Finally, in 2006, Reiman's version of Thank You for Smoking was released. By almost any measure the film was a success. After a showing at the Toronto Film Festival, Sacks was able to sell the movie to Fox Searchlight for "more than it cost to produce" (Rose, 2006). The movie grossed nearly $\$ 24.8$ million in the U.S. alone, and another $\$ 16$ million internationally; it also won 
ten awards, and was nominated for twenty others, including two Golden Globes (IMDb, n.d.).

In the film version of Thank You for Smoking, Nick Naylor's official title is Vice President of the Academy for Tobacco Studies, though he refers to himself as a lobbyist. Basically, he is the chief spokesperson for Conglomerated Tobacco. He announces at the beginning of the film: "Michael Jordan plays ball; Charles Manson kills people; I talk." (At the end of the movie, he'll repeat the same lines, adding, "Everyone has a talent.") Later, he tells his son's fifth grade class, "I talk for a living." The major story line involves Naylor's on-going discursive battle with Vermont Senator Ortolan Finistirre, a liberal anti-smoking zealot whose latest crusade is to label all packages of cigarettes with a skull-and-crossbones. Along the way, the divorced Naylor is trying hard to develop a relationship with his 12-year-old son, Joey. He also meets regularly with the self-named MOD Squad, or Merchants of Death; in addition to Naylor, there is Polly Bailey, who represents the alcohol industry, and Bobby Jay Bliss, who works for S.A.F.E.T.Y. (Society for the Advancement of Firearms and Effective Training for Youth). Together they commiserate over the various problems they face.

At one point, Naylor is threatened (live on Dennis Miller) and then kidnapped. He is later found, in National Mall, naked and covered in nicotine patches. Although the amount of nicotine involved should have been lethal, Naylor survives (the movie claims) because he was a heavy smoker for many years. Naylor is also, earlier, interviewed by reporter Heather Holloway, with whom he becomes sexually involved, and who later publishes an embarrassing exposé of Naylor's many dark secrets. The crisis this causes is, of course, easily resolved, as Naylor simply does what he does best, first humiliating Holloway by outing her, then appearing before the Senate subcommittee to testify, thereby reestablishing himself as the "Sultan of Spin." He subsequently (and fortuitously, it turns out) leaves The Academy of Tobacco Studies to create his own consulting firm.

Naylor's job is to make persuasive arguments in defense of the tobacco industry. Generally, Naylor's public appearances function to illustrate his rhetorical prowess. In the opening scene,

\footnotetext{
${ }^{1}$ All quotes from Thank You for Smoking. Dir. Jason Reitman. Perf. Aaron Eckhardt, Maria Bello, Adam Brody, Sam Elliott, Katie Holmes, Rob Lowe, William H. Macy, Robert Duvall. Fox Searchlight, 2006. DVD.
} 
Naylor is on The Joan Lunden Show as part of a panel that includes the president of Mothers Against Teen Smoking, the American Lung Association, Senator Finistirre's aide (Ron Goode), and "Cancer Boy" Robin Williger (a fifteen year-old diagnosed with cancer). Here, Naylor is clearly positioned as heavily outnumbered - trying to defend the poor beleaguered tobacco industry facing the overwhelming odds of public sentiment against smoking (a notion that will resurface periodically). But Naylor goes on the offensive, first by attacking the Senator's aide: "The Ron Goodes of this world want the Robin Willigers to die. And do you know why? So their budgets will go up. This is nothing more than trafficking in human misery and you [indicating Goode], sir, should be ashamed of yourself." Before Goode (or anyone else) can respond, Naylor announces Conglomerated Tobacco's plan to invest fifty million dollars aimed at preventing teen smoking, to which the audience, which had booed him initially, responds with enthusiastic applause, and Cancer Boy approvingly shakes Naylor's hand.

Naylor's main argument is perhaps better illustrated when he speaks to his son's fifth grade class on Career Day. There, Naylor explains what he does as a lobbyist: "I speak on behalf of cigarettes." When challenged by a girl who says "My mommy says cigarettes kill," Naylor points out that the child's mother - since she's not a doctor or scientific researcher - is "not exactly a credible expert, is she?" Naylor goes on to explain: "it's good to listen to your parents ... but if your parents told you chocolate was bad, would you believe them? ... Of course not, so perhaps instead of acting like sheep when it comes to cigarettes, you should find out for yourself." The scene, set as it is in an elementary classroom and early in the movie, is so outrageous it cannot but be funny. And relatively innocuous. Naylor is basically cast as ethically questionable and perhaps somewhat oblivious. But for Naylor, it is just another argument to be won. What is more, he will make basically the same argument throughout the film, as he acquires a more and more heroic luster - temporarily called into question, but reified with certainty by the film's conclusion.

The argument is made more seriously at the end of the film, when Naylor appears before the Senate Committee to argue against Senator Finistirre's proposed skull-and-crossbones label on cigarettes. There, Naylor uses a variety of rhetorical strategies, shifting the focus away from cigarettes by (for example) suggesting we put a skull-and-crossbones on airplanes and automobiles, and even cheese, since "heart disease is the real number one killer in America." He then presents a classic individual's right to choose argument. Admitting that cigarettes are harmful, he says, "I just 
don't see the point in a warning label for something people already know." His testimony can be usefully contrasted with the testimony given in support of Finistirre's skull-and-crossbones label. One witness explains that the skull-and-crossbones is necessary because studies show that the American people respond much more often to images than to text. A second, representing the Hispanic community, argues that warning labels in English discriminate against the non-English speaking population, and that the "skull-and-crossbones speak loudly in any language." While both men actually have valid arguments, they are made to appear ridiculous. Indeed, Mr. Herrera concludes that by not adopting the skull-and-crossbones, the makers of cigarettes are saying that they want "non-English speaking peoples to die."

At the same time, Senator Finnistire is himself clearly disingenuous, leading his witnesses to say specific things and trying to set up Naylor even before he testifies. Indeed, the Senator himself is demonstrably no better than Naylor - pursuing his own questionable agenda with no small degree of "moral flexibility." Following The Joan Lunden Show debacle, for example, Finistire castigates his aide for looking like an "asshole" (and thereby making the Senator look like an asshole), as well as for the aide's poor choice of "Cancer Boy":

Finistirre: Where in the hell did you find cancer boy?

Aide: He was supposed to be quite reliable - the Pulmonary Council was one of his references.

Finistirre: Fucking non-profits! When you're looking for a cancer kid, he should be hopeless. He should have trouble talking. He should have trouble breathing. He should be in a wheelchair, carrying a little goldfish in a Zip-lock bag. Hopeless.

Likewise, on Dennis Miller, Naylor points out that the Senator once called for American tobacco fields to be "slashed and burned," and later the same day appeared at a benefit for the American farmer, riding a tractor.

The Senator, then, is also guilty of spin, but unlike Naylor, he is also a hypocrite and a buffoon; in fact, his arguments are simply assumed to be ridiculous from the start. As the movie concludes (having lost the battle to brand cigarettes with a skulland-crossbones), he has launched a new campaign to digitally remove cigarettes from classic movies, not to change history, he says, but "improve" it. It is worth noting here that Heather Holloway - who, as the equally hypocritical representation of the 
news media, makes public the "true" Nick Naylor - loses her job and is last shown reporting the weather, live for a local southern Florida station, in what is being called "the Storm of the Century." She is literally blown off the screen.

In contrast, Naylor emerges victorious, glorified for his masterful use of rhetoric. After the Senate hearing, BR (his boss), who had cut him loose after the newspaper scandal, claps him on the back, saying "Good job, my boy. That whole individual choice thing - they ate that shit up." This is a significant moment that is easily overlooked. Both Nick and BR know that the "individual choice" argument is bullshit. In fact, in one staff meeting, BR refers specifically to teen smoking as "our bread and butter," and goes on to say, "We don't sell tic-tacs, for Christ's sake, we sell cigarettes. And they're cool, available, and addictive. The job is almost done for us." Following the Senate hearing, BR assumes Naylor will return to work for him, though Naylor instead leaves tobacco to found his own consulting firm, and is last shown advising three CEO's: "Gentlemen, practice these words in front of the mirror: Although we are constantly exploring the subject, currently there is no direct evidence that links cell phone usage to brain cancer." He remains a happy member of the M.O.D. Squad, which has added three new members, from oil, fast food, and nuclear power.

In his public performances, Naylor spins (or avoids) the truth, but he is careful to never actually lie. The "truth" - or some of it - however, is openly stated in and by the film through Naylor's own first-person narration, as well as a series of candid, behind-the-scenes discussions: Naylor strategizing with his boss(es) and co-workers, meetings with the MOD Squad, and conversations with Jeff Megall, a movie producer who is going to help them put cigarettes back into movies in a way that shows smoking is "cool" (Brad Pitt and Catherine Zeta-Jones smoking after sex). Within these conversations, we learn both the full extent of Naylor's awareness of the ethical ambiguity of his job and the "truth" behind cigarettes. At the beginning of the movie he admits, in first person narration, "I earn a living fronting an organization that kills 1200 people a day. Twelve hundred people. We're talking two jumbo jet plane loads of men, women and children. I mean, there's Attila, Genghis... and me, Nick Naylor. The face of cigarettes, the Colonel Sanders of nicotine." Somewhat later, Naylor explains to his son that his job requires "a certain moral flexibility," like that of a lawyer who defends the guilty. 
When pressed, Naylor offers a number of different justifications for the work he does. One of these, repeated a number of times throughout the film, is simply "to pay the mortgage." The truth is this is a hollow defense, and Naylor knows it. The first time he says this, during his initial interview with Holloway, he refers to it, in a narrative voiceover, as "the Yuppie Nuremburg Defense." Defending cigarettes, however, is elsewhere conflated with defending the defenseless (tobacco companies). For example, following the newspaper exposé and his subsequent firing, Naylor withdraws into a depression, from which he emerges via another conversation with his son, who tells Nick, "It's your job to be generally hated." Naylor then explains to the M.O.D. Squad that he realized he had a job to do: "Right there, looking into Joey's eyes, it all came back in a rush. Why I do what I do. Defending the defenseless, protecting the disenfranchised corporations that have been abandoned by their very own consumers: the logger, the sweatshop foreman, the oil driller, the land mine developer, the baby seal poacher...." Here, Nick is interrupted - clubbing baby seals, apparently, is going too far, even for gun advocate Bobby Jay Bliss (though apparently sweatshops and landmines are not). Nick says, "You're missing the point," though he does not go on to explain (and is drawn instead back to apologizing for telling Holloway about the M.O.D. Squad).

Naylor does not need to explain the point here, however, because the point has already been made: it is a dirty job, but somebody has to do it. Why not him? He is good at it. Great, even. In fact, much of the justification provided by the film is based on the simple fact that Naylor is successful at what he does. Finistirre and Holloway are reprehensible because they are hypocrites, spinning the truth to forward their own agendas; and they are selfrighteous, sanctimonious, and disingenuous. Naylor, on the other hand, may be a hypocrite, but he is also genuine - he knows exactly what he's doing and is morally flexible enough to do it.

It is likewise made clear that Naylor's public and private faces do not match, that despite what he says on television, he is, in fact, promoting cigarettes. After he announces the campaign to stop teen smoking, for example, Naylor is on his way to meet with The Captain when, in first person narration, he informs us:

Most people have this image in their heads of tobacco executives jet-setting around the world on private planes, eating foie gras as they count their money. Not me. I like to ride with the people. Know your clients. My people cram themselves into a tiny seat, pop a Xanex, 
and dream of the moment when they can stuff their face with fresh tobacco. If I can convince just one of these kids to pick up smoking, I've paid for my flight. Round trip.

The Captain, who chuckles over Nick's attack on the senator's aide on the Joan Lunden show ("you gave it to that son-of-bitch good," he says), gives the go-ahead for the fifty million dollar anti-teen smoking campaign, saying, "I sure hope it isn't too successful."

The film, then, does not hide the truth about smoking, or about the tobacco lobby, because, in one sense, it isn't really about smoking at all. It is about the function of public discourse. The movie plays on the tension between spin and truth-telling in order to make an argument about argument. It is forthcoming about the nature of spin as well as the "truth" about cigarettes - we get both the filtered (public) and unfiltered (private) stories, and even the private version is made public within the film. But the truth is neutralized, and spin normalized, by several key narrative strategies: (1) the portrayal of Naylor as a kind of hero, defending the defenseless corporations against overwhelming odds and emerging victorious; (2) the demonization of the specifically liberal opposition, in this case including both Finistirre (government) and Holloway (media); and (3) by the developing relationship between Naylor and his son, Joey.

That relationship serves, in part, to "humanize" Naylor, reinforcing his heroic qualities (Rose, 2006). But it also serves, via a series of conversations, to make explicit the film's argument about argument. In the first of these conversations, Joey has been given an assignment to write an essay on "why American government is the best government in the world." Naylor, outraged by the assignment, explains that there's no way to actually make that argument - based on what criteria? And can you really compare it to all other governments? Instead, Nick says, questions like this are what bullshit is for, and concludes, "that's the beauty of argument - when you argue correctly, you're never wrong." Thus, the film theorizes rhetoric at the same time that it illustrates a particular use (or uses) of rhetoric. Naylor later illustrates this theory of rhetoric by engaging Joey in a mock debate:

Nick: Okay, let's say that you're defending chocolate ice cream, and I'm defending vanilla. Now, if I were to say to you "Vanilla is the best flavor ice-cream," you'd say ... . Joey: No, chocolate is. 
Nick: Exactly, but you can't win that argument. So I'll ask you, 'So, you think chocolate is the be-all and end-all of ice-cream, do you?'

Joey: Yes, chocolate is all I need.

Nick: Well, I need more than chocolate, and for that matter I need more than vanilla. I believe we need freedom and choice when it comes to our ice-cream, and that, Joey Naylor, is the definition of liberty.

Joey: But that's not what we're talking about.

Nick: Ah, but that's what I'm talking about.

Joey: But you didn't prove that vanilla was the best.

Nick: I didn't have to. I proved that you're wrong. And if you're wrong, I'm right.

Joey: But you still didn't convince me.

Nick: But I'm not after you. [Gesturing to a crowd of people] I'm after them.

This basic theory is illustrated by Naylor's public appearances throughout the film, including most obviously his attack on the Senator's aide on The Joan Lunden Show, his attack on the Senator himself on Dennis Miller, and in his testimony before the Senate committee. More subtle is its political basis in an appeal to a certain, libertarian version of "democracy": Naylor's appeal to liberty in the debate with Joey, and the individual choice argument made before the Senate committee.

Thus, the movie both illustrates and advocates a peculiar version of the public sphere. Obviously, Naylor argues in the interests of corporate giants, which are portrayed as the oppressed victims of (big) government. It therefore privileges individual liberty, rejecting the concerns of the community as sanctimonious, ridiculous, and oppressive. Almost anything goes - without regard for truth or falsity, except that outright lying is understood to be ineffective and potentially dangerous. The principle is, as stated in Fox Searchlight's trailer, "Don't hide the truth, just filter it." Democratic deliberation - which depends on access to truth, or knowledge - is unnecessary, because everybody already knows.

\section{Public Discourse About the Movie}

Thus far I have been concerned only with the internal narrative of the film. Now I would like to turn to the external constellation of 
discourse that surrounds it. This includes, in this case, a broad array of reviews of the movie; the original book; interviews with both the book's author Christopher Buckley and the movie's writer and director, Jason Reitman; and Reitman's own description of discussion following a showing at UC Berkeley. These examples of public discourse around the movie bring into clearer focus the film's peculiar theory of public argumentation and its relationship to a libertarian notion of democracy.

The film itself was billed and promoted, and typically reviewed, as a satire of lobbyists and spin doctors, though this is a more accurate description of the original book than of Reitman's movie. Fox Searchlight called it "a fiercely satirical look at today's culture of spin!" Reviewers generally referred to it with positive phrases, such as "razor-sharp" (Puig, 2006; Feinberg, n.d.), "strong and unfiltered" (Jolin, n.d.), "savage and elegant" (Ebert, 2006), and "ingenious" (Arendt, 2006), though some called it "glib" (LaSalle, 2006), "scattershot" (Jolin, n.d.) and even "muddled" (Bradshaw, n.d.). Several pegged the movie as "avoiding anything like an actual point of view" (Shager, 2006), though they differed on whether this was a virtue or flaw (Axmaker, 2006; LaSalle, 2006). As Nick Shager (2006) wrote, "what satire demands is that a position, any position, is taken with regards to the topic at hand. Like its scumbag lobbyist, however, all that Thank You for Smoking really peddles is a smoggy cloud of 'moral flexibility." Mick LaSalle (2006) argued that the film is more "spoof" than "satire," "a litany of complaints followed by a shrug of the shoulders, a movie about the morass that can't see through the morass."

These few criticisms, however, tend to share with favorable reviews the perception of "equal-opportunity political skewering" (Dargis, 2006). The film "has appeal to all sides of the political spectrum," as Manohla Dargis (2006) wrote in USA Today; it is "even-handed in its skewering, taking aim squarely at our culture of political correctness and obsessive spin control" (see also Travers, 2006; Shager, 2006; Seibert, n.d.; Feinberg, n.d.; Rothbaum, 2006). On one hand, nobody misses the fact that Nick Naylor is a "cretin" and a "scumbag" (Shager, 2006). But they happily point out that "Naylor and his cronies are not the movie's only targets" (Rothbaum, 2006), that the politicians and newspaper reporters are as immoral and corrupt as the lobbyists. It is perhaps notable, then, with somewhat more than a little irony, that at least one reviewer admitted an inability to remember the ending of the movie (Longworth, 2006). 
In a glowing profile of Reitman, released shortly before the film, Brian D. Johnson (2006) hits closer to the mark. The movie, he writes, "is not really about tobacco.... It's an assault on liberal sanctimony" (emphasis added). Naylor, lobbyists in general, even the tobacco industry, corporate culture, and the "culture of spin" are used in the movie for comedic effect - but not in any way that is meaningfully satirical. The truth about lobbying is neutralized, not satirized. Attacks on Naylor within the movie are portrayed as unjustified; he is not attacked, assaulted, or ridiculed by the movie. His foil Senator Finnistirre - that paragon of liberal sanctimony is. So is Holloway, whose unethical behavior provides access to knowledge she would not otherwise have, and who is summarily punished by film's end. Naylor is not only victorious but redeemed, and his rhetoric justified, both by his success and by his appeal to a libertarian political position. The film thus valorizes a certain kind of spin (the Senator's rhetoric is not justified, nor is Holloway's reporting), while demonizing liberal politics. Liberal politics, in this sense, are caricatured as an infringement on the rights of individuals.

This is supported by a variety of statements by Reitman himself (and others). On encountering the book, he says, "It was love at first sight. That combination of ballsy humor and libertarian politics. I thought, this guy is similar to me. There are very few of us out there who are this fed up with liberal dogooders" (Johnson, 2006). On an episode of The Charlie Rose Show (2006) (which is included on the Thank You for Smoking DVD), Reitman appeared alongside author Christopher Buckley, producer David O. Sacks, and lead actor Aaron Eckhardt, on March 17, 2006 - just a few days before the movie's wide release. There, Reitman referred to the movie specifically as "a libertarian film." Sacks, when asked why he was interested in producing this movie (his first), explained: "I loved how the morality of the screenplay was inverted." Whereas the tobacco giants are usually "evil," and the reporters and politicians the heroes, "Naylor is the hero, you're rooting for him." Sacks goes on to say that, "We've made spin necessary. Nick Naylor is a spin doctor, but it's society's hypocrisy that makes spin necessary." Pressed rather gently on this point by Rose, Sacks continues, "We love our vices, and government's gone too far when it starts to clamp down on these things."

Eckhart emphasizes the "human aspect" of Naylor's character via the relationship to his son, which he calls "really the basis for the heart of the film." This "embellishment" (as Johnson called it), which Buckley admits was "entirely Jason's addition," is 
significant not just because of its role in "humanizing" Naylor, but because Naylor doesn't actually change as a result of their developing relationship. In the end, Naylor is basically the same person he was in the beginning; instead, his effort to be a father takes the form of turning Joey into a prodigy, a budding young slimeball. Moreover, Naylor's ex-wife also changes, from disapproving of Nick's involvement with their son to enthusiastically supporting the new Nick-in-training, who is crowned the Foggy Bottom Debating Society champion.

The resolution of the movie is all the more significant for its divergence from the book. Johnson (2006) writes, "Every major studio turned [the manuscript] down. He [Reitman] says they all wanted him to rewrite the ending so the hero would have a change of heart": Reitman says, "I got these notes from high-profile people, saying he has to go work for the Red Cross. I thought that was ridiculous." This is odd, to say the least, since at the end of the book, Naylor is on Larry King, discussing his book (Thank You for Smoking, which tells the whole sordid story), and professing a kind of change of heart: He is now working for "Clean Lungs 2000," trying to get people to stop smoking. In keeping with the book's satire, it is not entirely clear how genuine this change is, but Naylor is most certainly not squeaky clean and rather is doing what he has always done. Nor are these, in fact, the only "embellishments" made by Rietman. To begin with, the book's protagonist is not "The Sultan of Spin" at all, but merely bumbling his way through trying to defend the indefensible (rather than, as in the movie, the defenseless). The book is, in this sense, clearly satirizing lobbyists. The kidnapping and attempt on Naylor's life is actually orchestrated by BR, presumably in an effort to gain public sympathy for the tobacco lobby, and possibly because Nick appears to be a threat to his own position. Naylor is found, naked, in National Mall, with a sign around his neck: "Executed for crimes against humanity" (Buckley, 1994). This is followed by an F.B.I. investigation. Nick has been framed by a co-worker for arranging his own kidnapping and eventually goes to jail. In the movie, there is no indication of any this, excepting a reference to the sign found around his neck; and rather than reveal what the sign actually said, his M.O.D. Squad buddy Bobby Jay tells him only, "It was some pretty fucked up shit." One is left to assume that Naylor's assailants were merely anti-smoking crackpots.

I am not arguing, of course, that the movie should have followed the book more closely. But the changes Reitman made highlight the film's politics. They remove or neutralize virtually all of the significant barbs pointed at lobbying, big business, and 
corporate culture, in favor of a full-frontal assault on liberal government, liberal media, and especially liberal sanctimony. The relationship between this assault and models of public discourse is perhaps best illustrated by a story told by Reitman on The Charley Rose Show (and repeated by Johnson). He had been screening the film at college campuses across the country, and, according to Buckley, the students had been "eating it up." At Berkeley, Reitman relates, an older woman stood up during the discussion and let him have it for "not going after Big Tobacco and corporations for doing such evil things." Reitman rather gleefully recalls that the students booed her until she shut up; one student finally stood up and told the woman to "get over yourself" (Rose, 2006). "I loved it," Reitman said (Johnson, 2006).

This is a kind of microcosmic example of what the film itself does and says about public discourse. There is no real discussion or debate - Reitman is not willing (or perhaps able) to engage the woman in a discussion of why he has not gone after Big Tobacco or why he has chosen to construct the film in the way he has. There is just a lot of uncritical booing until the offending person is silenced.

\section{The Truth About Tobacco}

The film, however, gives the appearance of speaking the truth: at the very beginning Nick Naylor admits that smoking kills 1,200 people a day; his boss, BR, refers to teen smoking as their "bread and butter," and Naylor elsewhere confesses to trying to convince kids to start smoking; and in the end, before the Senate committee, Naylor acknowledges that smoking is harmful. But on another level, the movie obscures and in large part completely ignores the actual history of the tobacco industry and subsequent controversy.

As early as 1953, the major tobacco companies began conspiring to combat scientific evidence and sow doubt in the minds of the populace about the health-related aspects of smoking (McIntyre, 2018, p. 22). One internal memo of 1969 stated clearly that, "doubt is our product since it is the best means of competing with the 'body of fact' that exists in the minds of the general public" (Oreskes and Conway, 2010, p. 34). Although the tobacco companies themselves argued repeatedly, in a series of lawsuits, that there was "still no scientific proof that smoking causes lung cancer, emphysema, and other serious illnesses" (Brandt, 2009, p. 345), by 1994 there was no longer any serious debate about the health risks associated with smoking. The industry was also arguing (sometimes in the same lawsuits) that they were "not 
culpable because smokers were fully aware of the potential risks" (Brandt, 2009, p. 411). Thus, the grounds for debate subtly shifted to the issue of nicotine and addiction.

On February 28, 1994, ABC News' Day One program aired a story alleging that the industry had not only knowingly and intentionally suppressed information indicating that nicotine was addictive, but that they had used that information to manipulate nicotine levels in cigarettes. Internal documents, dating back at least to 1963, showed "the industry's knowledge and manipulation of the product's addictive quality" (Brandt, 2009, p. 402). For example, a 1979 memo from British American Tobacco stated, "We are searching explicitly for a socially acceptable addictive product. The essential constituent is most likely to be nicotine or a direct substitute for it"; in 1982, a Brown and Williamson document noted, "Nicotine is the addicting agent in cigarettes"; an R. J. Reynolds report from 1991 claimed, "We are basically in the nicotine business. ... Effective control of nicotine in our products should equate to a significant product performance and cost advantage"; and when the state of Minnesota filed suit against Big Tobacco later in 1994, additional documents showed "the industry found ways of boosting the nicotine dosage in cigarettes," including a process used by Philip Morris, B \& W, R. J. Reynolds, and Lorillard: "treating tobacco with ammonia to increase its 'nicotine kick"' (Public Citizen, 2015).

Six weeks after ABC's Day One story aired, the CEO's of the seven largest tobacco companies - later nicknamed the Seven Dwarves - testified before a congressional subcommittee. It is worth noting here that the movie Thank You for Smoking begins and ends with an image of the Seven Dwarves before the subcommittee. But the movie reinforces the popular view that the tobacco companies were called to testify regarding the harmful effects of cigarette smoking. In fact, they were called to testify in part because despite the health risks, the industry remained largely unregulated, unlike other companies that sold potentially dangerous products, and it was increasingly obvious that advertising was targeting children specifically. Rep. Henry Waxman, chair of the Energy and Commerce Subcommittee on Health and the Environment since 1979, pointed out in his opening remarks:

For decades, the tobacco companies have been exempt from the standards of responsibility and accountability that apply to all other American corporations. Companies that sell aspirin, cars and soda are all held to strict standards when they cause harm. We don't allow 
those companies to sell goods that recklessly endanger consumers. We don't allow them to suppress evidence of dangers when harm occurs. We don't allow them to ignore science and good sense. And we demand that when problems occur, corporations and their senior executives be accountable to Congress and the public (Inside the Tobacco Deal, 1994).

Waxman, a Democrat from California, went on to say:

Nearly a half million Americans die every year as a result of tobacco. This is an astounding, almost incomprehensible statistic. Imagine our nation's outrage if two fully loaded jumbo jets crashed each day, killing all aboard. Yet that's the same number of Americans that cigarettes kill every 24 hours (Inside the Tobacco Deal, 1994).

This is actually stated at the very beginning of the film, not by Waxman, but by Nick Naylor (in a narrative voiceover), and the film's primary antagonist, Senator Finistirre, is an obvious caricature of Waxman.

In their testimony, and despite the internal documents showing they knew nicotine was addictive, the Seven Dwarves continued to deny it. William Campbell, President and CEO of Phillip Morris, stated quite clearly, "cigarette smoking is not addictive," and "Phillip Morris does not manipulate nor independently control the level of nicotine in our products" (Inside the Tobacco Deal, 1994). Each of the other CEOs made virtually the same claims. The notion that nicotine is not addictive, and should not be regulated as a "drug," was based primarily in appeals to the fact that as many as 40 million smokers had quit by 1988 , that smoking "is not intoxicating" and "does not impair judgment," and that the industry's own research had effectively concluded as much (Brandt, 2009, p. 345). The CEOs were later found not to have perjured themselves because each specifically stated that he did not believe nicotine was addictive, even though (as the transcript shows), Campbell stated this elsewhere as a fact.

By 1997, 31 states had filed suit based on the hazards to public health and ensuing Medicaid costs (Brandt, 2009, pp. 415416). The tobacco companies spent a record $\$ 35.5$ million on lobbying that year (up 23 percent from 1996), and $\$ 40$ million in just two months of 1998 on radio and television ads in order to kill a Global Settlement Agreement, a bill introduced by John McCain (Brandt, 2009, p. 428). Later that year, however, a Master Settlement Agreement, worth about $\$ 246$ billion, was negotiated. 
The MSA dropped "all provisions requiring congressional approval, such as FDA regulation," as well as "mandates for stronger package warnings, tighter enforcement on sales to youth, stronger public smoking bans, and look-back provisions to reduce youth smoking" (Brandt, 2009, p. 432). And although the industry agreed to fund a national foundation devoted to public health and the reduction of smoking, and to modest restrictions on advertising and promotion (R.J. Reynolds had previously agreed that Joe Camel and other cartoon characters would be prohibited), there was no specific mandate on how the money paid to the states would be spent; by 2005, only 4 percent of $\$ 41$ billion paid to the states had gone to support educational and cessation programs; most of it had been used instead to balance state budgets (Brandt, 2009, p. 435).

In 2006, the same year Thank You for Smoking was released, U.S. District Judge Gladys Kessler ruled on a suit filed by the Clinton administration (in 1999) under RICO (the Racketeer Influenced and Corrupt Organizations Act). Judge Kessler ruled that the major tobacco companies and their "research" institutions had, among other things, "falsely denied, distorted, and minimized the significant adverse health consequences of smoking for decades"; "concealed and suppressed research data and other evidence that nicotine is addictive," while continuing publicly to deny the fact, in addition to intentionally manipulating the level of nicotine in cigarettes; and "intentionally marketed to young people" (United States $v$. Philip Morris, 2006). Moreover, she argued, even eight years after the MSA, the companies had "not ceased engaging in unlawful activity" (United States $v$. Philip Morris, 2006, pp. 1604-1605). Her ruling was upheld by a U.S. Court of Appeals in May, 2009, and imposed a variety of penalties. Even so, due to a previous ruling (which limited financial penalties under RICO), the companies paid nothing more than the government's court costs.

\section{Conclusion}

Although it is tempting, in light of Kessler's ruling and increasingly restrictive anti-smoking legislation, to read this as a case of public discourse functioning the way it should, Thank You for Smoking tells a different story. The film, no doubt, enjoyed a much larger audience than Judge Kessler's 1,700 page opinion. It is true that the percentage of U.S. adults who smoke has steadily declined, from over $25 \%$ in 1990 to $15.5 \%$ in 2016 (Centers for Disease Control, 2019). Teen smoking has likewise declined from almost 
19\% in 2011 to $10.4 \%$ in 2017 (Truth Initiative, 2018). But the number of smokers worldwide remains high at $19 \%$, and, according to the World Health Organization, $80 \%$ of them are in low- and middle-income countries (Tobacco, 2015).

Of greater significance is what Thank You for Smoking does - utterly obfuscating the truth about the tobacco controversy and what it says about public discourse. In this version of the public sphere, post-truth spin is necessary, justified, and ultimately valorized as a critical means of defending the very foundations of democracy. It has, in fact, been weaponized. As Lee McIntyre (2018) points out, "Post-truth amounts to a form of ideological supremacy, whereby its practitioners are trying to compel someone to believe in something whether there is good evidence for it or not. And this is a recipe for political domination" (p. 13). The film - indeed, the post-truth public sphere effectively neutralizes any notion of truth by transforming fact(s) into mere, competing "opinions," and thus expunging actual critical, deliberative rhetoric from the public sphere.

Copyright (C) 2021 Michael Donnelly 


\section{Reference List}

Arendt, P. (2006, June 20). "Thank you for smoking" [Review of the movie Thank You for Smoking by J. Reitman]. BBC. Retrieved from www.bbc.co.uk/films.

Axmaker, Sean. (2006, March 30). "Brazen 'Thank You for Smoking' is a breathtaking satire" [Review of the movie Thank You for Smoking by J. Reitman]. Seattle PostIntelligencer. Retrieved from www.seattlepi.com.

Bradner, Eric. (2017, January 23). "Conway: Trump White House Offered 'Alternative Facts' on Crowd Size.” CNN.com. Retrieved from https://www.cnn.com/2017/01/22/politics/kellyanneconway-alternative-facts/index.html

Bradshaw, P. (2006). "Thank you for smoking” [Review of the movie Thank You for Smoking by J. Reitman]. The Guardian. Retrieved from www.guardian.com.

Brandt, A. (2009). The cigarette century: The rise, fall, and deadly persistence of the product that defined America. New York: Basic Books.

Buckley, C. (1994). Thank you for smoking. New York: Random House.

Buckley, C. (2006, March 20). "How to break into movies in only 12 years." Time.

Burke, K. (1969). A rhetoric of motives. Berkeley: University of California Press.

Calhoun, C. (1992). Habermas and the public sphere. Cambridge: MIT Press.

Centers for Disease Control and Prevention. (2019, January 18). "Smoking is down, but almost 38 million American adults still smoke" [Press Release]. Retrieved from https://www.cdc.gov/media/releases/2018/po118smoking-rates-declining.html>

Dargis, M. (2006, March 17). Smoke 'em if you got 'em; his career depends on it [Review of the movie Thank You for Smoking by J. Reitman]. The New York Times. Retrieved from movies.nytimes.com.

Ebert, R. (2006, March 23). "Thank you for smoking” [Review of the movie Thank You for Smoking by J. Reitman]. Retrieved from Rogerebert.com. 
Feinberg, L. (n.d.). "Thank you for smoking” [Review of the movie Thank You for Smoking by J. Reitman]. Cinemablend.com.

Fox Searchlight. (2006). "Thank you for smoking." Foxsearchlight.com.

Gomez, M. (2018, August 19). Giuliani says 'truth isn't truth' in defense of Trump's legal strategy. The New York Times. Retrieved from https://www.nytimes.com/2018/o8/19/us/giuliani-meetthe-press-truth-is-not-truth.html

Hirschfeld Davis, J. \& Rosenberg, M. (2017, January 21). With false claims, Trump attacks media on turnout and intelligence rift. The New York Times.

IMDb. (n.d.). “Thank you for smoking.” IMDb.com.

"Inside the Tobacco Deal: Nicotine and Cigarettes." (1994, April 14). PBS Frontline. http://www.pbs.org/wgbh/pages/frontline/shows/settleme $\mathrm{nt} /$ timelines/april94.html

Johnson, B. (2006, March 24). Jason Reitman is on fire. Maclean's. Retrieved from www.macleans.ca.

Jolin, D. (n.d.). "Thank you for smoking" [Review of the movie Thank You for Smoking by J. Reitman]. Empire Magazine. Retrieved from www.empireonline.com.

LaSalle, M. (2006, March 24). In 'Thank You for Smoking,' it's not only the slick tobacco flack who's amoral. [Review of the movie Thank You for Smoking by J. Reitman]. San Francisco Chronicle Retrieved from www.sfgate.com.

Longworth, K. (2006, January 22). "Thank you for smoking" [Review of the movie Thank You for Smoking by J. Reitman]. Moviefone. Retrieved from news.moviefone.com.

McIntyre, L. (2018). Post-truth. Cambridge: MIT Press.

Olson, G. (1990). Jacques Derrida on rhetoric and composition: A conversation. JAC: A journal of composition theory, 1O(1), 1-20.

Oreskes, N., \& Conway, E. (2010). Merchants of doubt: How a handful of scientists obscured the truth on issues from tobacco smoke to global warming. New York: Bloomsbury.

Peters, J. D. (1993). Distrust of representation: Habermas on the public sphere. Media, culture and society, 15, 541-71. 
Public Citizen. (2015). Don't be fooled again: A report on the tobacco industry's lies and deceptions. Retrieved from http://www.citizen.org/congress/article_redirect.cfm?ID= 907.

Puig, C. (2006, March 16). Thank you for smoking is a breath of fresh air [Review of the movie Thank You for Smoking by J. Reitman]. USA Today Online. Retrieved from usatoday3o.usatoday.com.

Reitman, J. (Director). (2006). Thank You for Smoking [Film]. Fox Searchlight.

Roberts-Miller, P. (2004). Deliberate conflict: Argument, political theory, and composition classes. Carbondale: Southern Illinois University Press.

Rose, C. (2006). Interview with Jason Reitman, Christopher Buckley, Aaron Eckhardt, and David Sacks. The Charley Rose Show. Thank You for Smoking. [DVD] Dir. Jason Reitman. Fox Searchlight.

Rothbaum, R. (2006, March). "Must-see little movie: Thank you for smoking." [Review of the movie Thank You for Smoking by J. Reitman]. O, The Oprah Magazine. Retrieved from www.oprah.com/omagazine.

Seibert, P. (n.d.). "Thank you for Smoking" [Review of the movie Thank You for Smoking by J. Reitman]. Rotten Tomatoes. Retrieved from www.rottentomatoes.com.

Shager, N. (2006, February 23). "Thank you for Smoking” [Review of the movie Thank You for Smoking by J. Reitman]. Slant Magazine. Retrieved from www.slantmagazine.com.

Travers, P. (2006, March 22). "Thank you for Smoking” [Review of the movie Thank You for Smoking by J. Reitman]. Rolling Stone.

Truth Initiative. (2018, September 5). "Young Adult Smoking Rate Drops to $10 \%$." Retrieved from https://truthinitiative.org/research-resources/tobaccoprevention-efforts/young-adult-smoking-rate-drops-10.

World Health Organization. (2015, July 6). "Tobacco" (Fact Sheet No. 339). Media Centre. Retrieved from http://www.who.int/mediacentre/factsheets/fs339/en/.

United States $v$. Philip Morris. (2006, August 17). U.S. District Court for the District of Columbia (Civil Action No. 992496). Amended Final Opinion. Retrieved from 
http://publichealthlawcenter.org/sites/default/files/resour ces/doj-final-opinion.pdf 